Check for updates

The BMJ

Cite this as: $B M J 2021 ; 374: n 1762$ http://dx.doi.org/10.1136/bmj.n1762 Published: 12 July 2021

\title{
Covid-19: Doctors warn of "disconnect" between NHS pressure and lifting of restrictions
}

\section{Elisabeth Mahase}

The number of patients waiting for treatment through the NHS in England exceeded 5.3 million at the end of May 2021, with more than 330000 patients waiting more than 52 weeks, new figures show. ${ }^{1}$

The latest data, released by NHS England, reported that $67.4 \%$ of the patients waiting to start treatment at the end of May waited up to 18 weeks. This is far below the NHS standard, which states that $92 \%$ of patients should have to wait no more than 18 weeks from referral to treatment.

Medical leaders have said the figures highlighted the "disconnect" between what doctors and healthcare professionals were currently experiencing and the government's decision to lift all covid-19 restrictions on 19 July.

Simon Walsh, deputy chair of the BMA's Consultants Committee, said, "There is ... enormous pressure on hospitals, overcrowding in waiting rooms, and soaring emergency attendances. Mandatory wearing of masks in confined public spaces, improved ventilation, and maintaining social distancing where possible should be non-negotiable to prevent a spike in infections which could push all NHS services to breaking point and will reverse any of the progress that has been started by doctors tackling the waiting lists."

During May this year around 1.5 million patients started on the referral-to-treatment pathway, while just under 1.2 million who were already on the pathway started treatment.

The UK government has said it plans to remove all covid-19 restrictions, including mandatory face masks in public spaces and social distancing, on 19 July. This is despite the health and social care secretary for England, Sajid Javid, saying that infections could climb to 100 ooo or more a day by the end of the month. On 7 July the UK reported more than 30000 new daily cases and rises of more than $40 \%$ in hospital admissions and deaths. ${ }^{2}$

Walsh added, "The link between infections and hospitalisations has been weakened but not been broken, so right now there needs to be time to allow the NHS to tackle the waiting lists, support those patients who need the most urgent care, and prevent a catastrophic third wave of covid-19."

In response to the waiting list figures the Royal College of Surgeons of England urged the government to invest in surgical hubs that separate planned surgical services from emergency services, to help services withstand infectious outbreaks, and to train more staff.

College council member and consultant general and vascular surgeon Stella Vig said, “An operation can enable someone to return to work and an independent life. As a country, we cannot afford to let waiting times for operations get ever longer. Covid-19 hospital admissions remain relatively low, thanks to the successful vaccination programme. But with cases rising steeply, and emergency departments under pressure, we need government investment in surgical hubs and staff now, to stop surgery slowing down again."

Siva Anandaciva, chief analyst for the health think tank the King's Fund, said, "Even as the country emerges from the pandemic and more restrictions are lifted, the crisis is far from over for health and care services and exhausted staff. NHS services face competing demands for their limited resources and a coherent national strategy for balancing these pressures is urgently needed."

Correction: On 12 July we clarified the numbers in the sentence about numbers of patients on the referral-to-treatment pathway.

NHS England and NHS Improvement. Statistical press notice: NHS referral to treatment (RTT) waiting times data. May 2021. https://www.england.nhs.uk/statistics/wp-content/uploads/sites/2/2021/07/May21-RTTSPN-publication-69343.pdf.

2 Wise J. Covid-19: Ending all restrictions in England on 19 July "dangerous and premature," say experts. BMJ2021;374:n1751 doi: 10.1136/bmj.n1751 pmid: 34244245

This article is made freely available for use in accordance with BMJ's website terms and conditions for the duration of the covid-19 pandemic or until otherwise determined by BMJ. You may use, download and print the article for any lawful, non-commercial purpose (including text and data mining) provided that all copyright notices and trade marks are retained. 